\title{
Highway to the heart or one more for the road? The continued life of direct aortic access for transcatheter aortic valve replacement
}

\author{
Michael J. Reardon, MD, ${ }^{a}$ and Neal S. Kleiman, MD $^{\mathrm{b}}$ \\ From the Departments of ${ }^{\mathrm{a} C}$ ardiovascular Surgery and ${ }^{\mathrm{b}}$ Cardiology, Houston Methodist Hospital, Houston, Tex. \\ Disclosures: Authors have nothing to disclose with regard to commercial support. \\ Received for publication July 9, 2016; accepted for publication July 12, 2016; available ahead of print Aug 24, \\ 2016. \\ Address for reprints: Michael J. Reardon, MD, 6550 Fannin, Houston, TX 77030 (E-mail: mreardon@ \\ houstonmethodist.org). \\ J Thorac Cardiovasc Surg 2016;152:1616-7 \\ $0022-5223 / \$ 36.00$ \\ Copyright (C) 2016 by The American Association for Thoracic Surgery \\ http://dx.doi.org/10.1016/j.jtcvs.2016.07.038
}

The momentum is clear: Transcatheter aortic valve replacement (TAVR) has become established as the treatment of choice in many high-risk symptomatic patients with severe aortic stenosis and is very likely to become established in lower-risk patients as well. Randomized clinical trials have proven TAVR to be equivalent or superior to open surgical aortic valve replacement in highrisk patients, making it an increasingly popular alternative especially in older patients in this group. ${ }^{1,2}$ Recent results for the balloon-expandable valve in the Placement of Aortic Transcatheter Valves IIA randomized trial (NCT01314313) in intermediate-risk patients suggest that use in this patient group also may be reasonable. ${ }^{3}$ These findings will be supplemented by the results from the Surgical Replacement and Transcatheter Valve Implantation intermediate-risk randomized trial (NCT01586910) for the self-expanding CoreValve (Medtronic, Minneapolis, Minn) in 2017. In addition, 2 low-risk randomized trials, Placement of Aortic Transcatheter Valves 3 (NCT02675114) and Medtronic TAVR in low-risk patients (NCT02701283), are currently enrolling. TAVR clearly is important to any valve program and surgeons interested in leading in the area of structural heart disease. As devices become smaller, easier to implant, and less likely to result in paravalvular leaks, TAVR will at some point become a requisite for any cardiologist or surgeon interested in treating patients with aortic valve disease. With the currently available commercial TAVR valves, a transfemoral (TF) approach is possible in more than $90 \%$ of patients and is generally considered the frontline approach. ${ }^{4}$ However, it is important to remember that not all patients requiring TAVR are suitable for this approach. When TF access is not possible, an alternative access approach must be considered if the procedure is to be successful. Numerous alternative access approaches that do not require transgression of the chest wall have been described, including trans-subclavian, transcarotid, iliac conduit, and transcaval access to the ascending aorta. Occasionally, when even these approaches have contraindications, a direct aortic (DA) or transapical (TA)

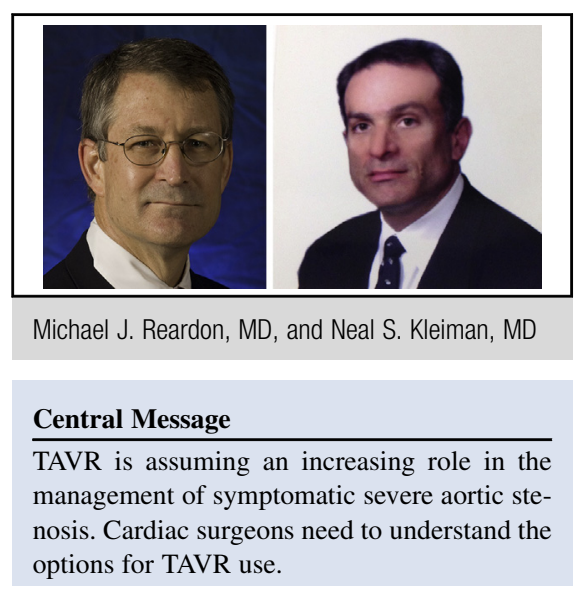

See Article page 1611.

approach must be considered, both of which require surgical exposure. Because of the way valves must be mounted on delivery catheters, the TA approach is limited largely to the Sapien (Edwards Lifesciences, Irvine, Calif) family of valves, and there has been suggestion that when left ventricular (LV) dysfunction is present (which is the case in approximately one third of patients undergoing $\mathrm{TAVR}^{5}$ ), the TA approach may not allow the same level of LV recovery as a TF TAVR. ${ }^{6}$ The DA approach has been used extensively with both the Sapien family of valves and the CoreValve/ Evolut R valves (CoreValve, Medtronic, Inc., Minneapolis, Minn). It has also been described with the mechanically expandable Lotus valve (Boston Scientific Corporation, Los Gatos, Calif) ${ }^{7}$ and the self-expanding Portico valve (St. Jude Medical, Inc., St. Paul, Minn). ${ }^{8}$ With the DA approach in the self-expanding valve trial, there was no difference in LV recovery between the TF and DA approaches, which makes the DA access desirable when needed as an alternative. ${ }^{9}$ Cardiac surgeons are well advised to understand this approach along with when and how it is best used.

In this issue of the Journal, Bushnaq and co-authors ${ }^{10}$ describe the technical use of DA access with the fully repositionable and retrievable nonmetallic Direct Flow Medical valve (Santa Rosa, Calif). The study is a small one, with only 15 cases requiring DA access of 55 total cases treated with the nonmetallic valve system. These small numbers preclude definitive statements about clinical outcomes other than to point out that the procedure can be done with apparent safety and effectiveness. However, 15 of 55 (27\%) seems a 
relatively high proportion, raising the question of why the TF approach (or at least non-DA) was possible in only $73 \%$ of their cases? This is very divergent from most current standards and raises the question of patient selection.

One might (or perhaps must) ask why such a report merits attention because the DA approach has already been well described $^{11}$ and why surgeons should take note. The reporting group has extensive TAVR and surgical aortic valve replacement experience. The strength of the article is that the technical aspects of the DA approach unique to the Direct Flow Medical valve are well described. The nonmetallic repositionable valve has already received CE mark in Europe and is currently enrolling in the United States in the Transcatheter Aortic Valve Replacement System U.S. Pivotal trial (NCT02163850). In this trial, only TF access is allowed. This article may provide the impetus for the Food and Drug Administration to allow a DA nested registry to be added to the Transcatheter Aortic Valve Replacement System U.S. Pivotal trial, thereby increasing the number of carefully characterized patients who have undergone DA for TAVR. As additional percutaneous valves receive regulatory approval for commercial use in the United States, forward-thinking heart teams will want to understand their use and access options. This will increase patient options for local heart teams and hopefully will foster competition that may eventually bring down the high price of the current commercially available valves, allowing economic viability of TAVR programs to improve.

To say TAVR has exploded on the world of cardiac valve disease may well be unfair to the power of explosions. The growth of TAVR and the iterative improvements have occurred at a breathtaking rate and show no signs of abating soon. The increasingly minimalist approach to TAVR has led some to question whether an operating room is required for the procedure at all and whether surgical involvement is still needed. The current report is one small addition to this arsenal but illustrates the need for surgeons to remain fully engaged contributors to this momentum. This small addition moves the field forward and is good for cardiac surgeons, heart teams, and patients. One more for the road? Sure.

\section{References}

1. Reardon MJ, Adams DH, Kleiman NS, Yakubov SJ, Coselli JS, Deeb GM, et al. 2-year outcomes in patients undergoing surgical or self-expanding transcatheter aortic valve replacement. J Am Coll Cardiol. 2015;66:113-21.

2. Mack MJ, Leon MB, Smith CR, Miller DC, Moses JW, Tuzcu EM, et al. 5-year outcomes of transcatheter aortic valve replacement or surgical aortic valve replacement for high surgical risk patients with aortic stenosis (PARTNER 1): a randomised controlled trial. Lancet. 2015;385:2477-84.

3. Leon MB, Smith CR, Mack MJ, Makkar RR, Svensson LG, Kodali SK, et al Transcatheter or surgical aortic-valve replacement in intermediate-risk patients. N Engl J Med. 2016;374:1609-20.

4. Abu Saleh WK, Tang GH, Ahmad H, Cohen M, Undemir C, Lansman SL, et al. Vascular complication can be minimized with a balloon-expandable, re-collapsible sheath in TAVR with a self-expanding bioprosthesis. Catheter Cardiovasc Interv. 2016;88:135-43.

5. Dauerman HL, Reardon MJ, Popma JJ, Little SH, Cavalcante JL, Adams DH, et al. Early recovery of left ventricular systolic function after CoreValve transcatheter aortic valve replacement. Circ Cardiovasc Interv. 2016;9.

6. Blackstone EH, Suri RM, Rajeswaran J, Babaliaros V, Douglas PS, Fearon WF, et al. Propensity-matched comparisons of clinical outcomes after transapical or transfemoral transcatheter aortic valve replacement: a placement of aortic transcatheter valves (PARTNER)-I trial substudy. Circulation. 2015;131:1989-2000.

7. Bapat V, Asrress KN, Boix R, Lim ZY, Hancock J, Redwood SR. Transaortic transcatheter aortic valve implantation using the Lotus valve: first-in-man experience. EuroIntervention. 2016;12:389-93.

8. Chandrasekhar J, Glover C, Labinaz M, Ruel M. First direct aortic retrievable transcatheter aortic valve implantation in humans. Can J Cardiol. 2014;30: 1461.e9-11.

9. Reardon MJ, Adams DH, Coselli JS, Deeb GM, Kleiman NS, Chetcuti S, et al Self-expanding transcatheter aortic valve replacement using alternative acces sites in symptomatic patients with severe aortic stenosis deemed extreme risk of surgery. J Thorac Cardiovasc Surg. 2014;148:2869-76. e1-7.

10. Bushnaq H, Metz D, Petrov A, Frantz S, Hofmann U, Raspé C, Treede H. Direc aortic access for transcatheter aortic valve replacement with a fully repositionable and retrievable non-metallic valve system. J Thorac Cardiovasc Surg. 2016;152:1611-5.

11. Ramlawi B, Bedeir K, Barker C, Lin CH, Kleiman N, Reardon M. Direct aortic and subclavian access for transcatheter aortic valve replacement: decision making and technique. J Thorac Cardiovasc Surg. 2014;148:353-6. 